\title{
Crystal growth and characterization of $\mathrm{Li}_{x} \mathrm{La}_{(1-x) / 3} \mathrm{NbO}_{3}$ using Czochralski method
}

\author{
Shuya MINEGISHI ${ }^{1}$, Takuya HOSHINA ${ }^{1}$, Takaaki TSURUMI', \\ Kheirreddine LEBBOU ${ }^{2}$ and Hiroaki TAKEDA ${ }^{1,3, \dagger}$ \\ ${ }^{1}$ School of Materials and Chemical Technology, Tokyo Institute of Technology, Meguro, Tokyo 152-8552, Japan \\ ${ }^{2}$ Institut Lumière Matière, UMR5306 CNRS, Universite de Lyon 1, 69622 Villeurbanne Cedex, France \\ ${ }^{3}$ Graduate School of Science and Engineering, Saitama University, 255 Shimo-Okubo, Sakura-ku, Saitama 338-8570, Japan
}

\begin{abstract}
Single crystals of $\mathrm{Li}_{x} \mathrm{La}_{(1-x) / 3} \mathrm{NbO}_{3}$ were grown in air using Czochralski method from La-poor melt. The lithiumion conductivity of the crystals was measured. The length and maximum diameter of the boule grown were 23 and $20 \mathrm{~mm}$, respectively. The boule contained no inclusions but was covered with a very thin polycrystalline film of $\mathrm{LaNbO}_{4}$ and $\mathrm{LiNbO}_{3}$ in its upper region. The composition of the crystals grown was estimated to be $x=0.15$ and the starting melt composition was $x=0.20$. The ionic conductivity of the crystal was anisotropic with $\sigma_{[100]}=$ $2.8 \times 10^{-4} \mathrm{~S} \mathrm{~cm}^{-1}$ and $\sigma_{\mid 001]}=9.7 \times 10^{-5} \mathrm{~S} \mathrm{~cm}^{-1}$ at $306 \mathrm{~K}$. The activation energy, $E_{\mathrm{a}}$ of these conductivities was almost the same in the range of $0.28-0.29 \mathrm{eV}$. Further, we discussed the anisotropic lithium-ion conductivity of the crystal.
\end{abstract}

(02020 The Ceramic Society of Japan. All rights reserved.

Key-words : Lithium-ion conductivity, Crystal growth, Perovskite, Niobate, Anisotropy

[Received February 2, 2020; Accepted April 7, 2020]

\section{Introduction}

Currently, various electronic devices such as notebook computers and smart phones are ubiquitous. Hence, lithium-ion batteries (LIBs) are primarily used to satisfy the demand for smaller and higher-capacity batteries because of their high energy density. Although liquid electrolytes have been used conventionally in LIBs, LIBs demonstrate certain drawbacks, such as electrolyte leakage and fire. All solid-state LIBs are expected to solve these problems and offer significant advantages, such as thermal stability and large potential windows to enable the use of high-voltage cathode materials and/or metallic lithium anodes. ${ }^{1)-3)}$ In particular, sulfide solid electrolytes are expected to be used in next-generation LIBs because of their high ionic conductivity, $\sigma$, of $10^{-2} \mathrm{~S} \mathrm{~cm}^{-1}$, which is higher than those of oxides. ${ }^{4)}$ However, sulfide solid electrolytes react with the moisture in the atmosphere and produce hydrogen sulfide gas. Therefore, oxide solid electrolytes, such as perovskite structures [e.g. $\mathrm{La}_{2 / 3-x} \mathrm{Li}_{3 x} \mathrm{TiO}_{3}$ (LLTO), ${ }^{5)-10)} \mathrm{Li}_{x} \mathrm{La}_{(1-x) / 3} \mathrm{NbO}_{3}$ (LLNbO) $\left.{ }^{11)-16)}\right]$ and garnet electrolytes (e.g. $\mathrm{Li}_{7} \mathrm{La}_{3} \mathrm{Zr}_{2} \mathrm{O}_{12}{ }^{17), 18)}$ ) are promising candidates because of their high chemical stability and high $\sigma$.

Corresponding author: H. Takeda; E-mail: htakeda@ceram. titech.ac.jp, takeda@apc.saitama-u.ac.jp

* Preface for this article: Dol http://doi.org/10.2109/jcersj2. 128.P8-1
In recent years, significant effort has been made to grow single crystals of oxide solid electrolytes for evaluating the intrinsic lithium-ion conductivity without the effect of grain boundaries in ceramic polycrystalline state. ${ }^{19)-24)}$ The growth methods include the floating zone, ${ }^{19)}$ Bridgman, ${ }^{20), 21)}$ and traveling solvent floating zone methods. ${ }^{22)-24)}$ Another bulk growth method is the Czochralski (Cz) method, which is a conventional method used to produce $\mathrm{Si}$ ingots. Compared to the other methods, the advantages of the $\mathrm{Cz}$ method are as follows:

1) the growth of bulk crystals is reproducibly performed,

2) the crystal grown is free from mechanical stress because the crystal is not in contact with the crucible, and

3) growth orientation can be selected arbitrarily.

To the best of our knowledge, few reports regarding the crystal growth of oxide solid electrolytes by the $\mathrm{Cz}$ method exist in literature. An optimized growth condition of the $\mathrm{Cz}$ method promotes the production of substrates for the solid electrolyte of LIBs.

In this study, we selected LLNbO as an oxide electrolyte example. LLNbO can be used as a solid electrolyte for all solid-state LIBs as its ionic conductivity is larger than $\left.\left.\left.\left.1 \times 10^{-4} \mathrm{~S} \mathrm{~cm}^{-1}, 11\right)-13\right), 20\right), 23\right)$ comparable to LLTO. ${ }^{5)-11), 19)}$ It is difficult to reduce the valence of $\mathrm{Nb}$ in LLNbO at high temperatures and in low oxygen partial pressures compared with the Ti in LLTO. Moreover, a platinum crucible 
can be used because the melting temperature of the $\mathrm{LLNbO}$ is lower than $1400^{\circ} \mathrm{C} .^{25)}$ Use of a platinum crucible enables to apply high oxygen partial pressures in the growth atmosphere. This prevents the volatilization of $\mathrm{Li}$ and reduction of $\mathrm{Nb}$. A conventional crystal structure of LLNbO is shown in Fig. 1. ${ }^{26)}$ Here, La ions and vacancies at $A$-sites in the perovskite $A B \mathrm{O}_{3}$ structure of the parent $\mathrm{La}_{1 / 3} \mathrm{NbO}_{3}$ are ordered within alternate $(001)$ planes and doubles the parameter $c$ of the cubic perovskite type cell. $\mathrm{Li}^{+}$ions are substituted for the occupied and vacant sites of $\mathrm{La}$ in the La-occupied layers. Anisotropic lithium-ion conduction along [100] and [100] has been reported previously. ${ }^{21), 23)}$ However, the activation energy of lithiumion conductivity activation along [100] and [100] has not been discussed.

In this study, LLNbO single crystals were grown using the $\mathrm{Cz}$ method. The starting material composition was

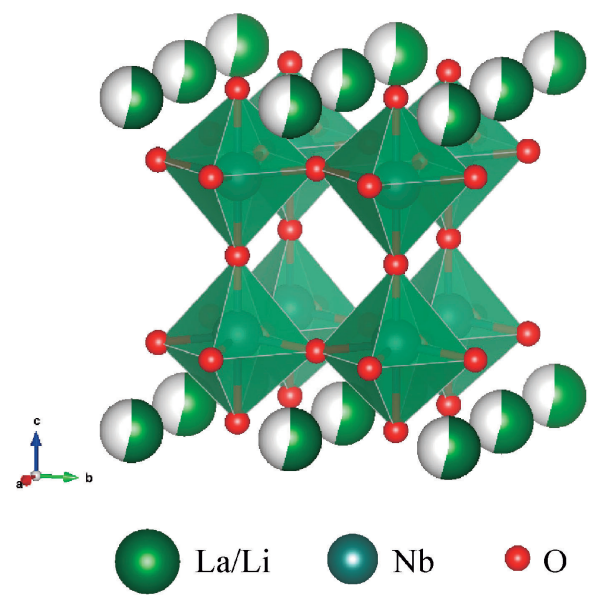

Fig. 1. Schematic of crystal structure of $\mathrm{Li}_{x} \mathrm{La}_{(1-x) / 3} \mathrm{NbO}_{3}$. optimized to grow inclusion-free crystals. After determining the lithium-ion conductivity and its activation energy, we discuss anisotropic lithium-ion conductivity in LLNbO crystal from the site percolation perspective.

\section{Experimental}

$\mathrm{Li}_{2} \mathrm{CO}_{3}$ and $\mathrm{Nb}_{2} \mathrm{O}_{5}$ powders with $99.95 \%$ purity and $\mathrm{La}_{2} \mathrm{O}_{3}$ powder with $99.9 \%$ purity were used as starting materials. First, we synthesized the $\mathrm{LiNbO}_{3}$ phase using $\mathrm{Li}_{2} \mathrm{CO}_{3}$ and $\mathrm{Nb}_{2} \mathrm{O}_{5}$ to prevent the volatilization of $\mathrm{Li}$. The $\mathrm{Li}_{2} \mathrm{CO}_{3}$ and $\mathrm{Nb}_{2} \mathrm{O}_{5}$ powders were mixed using a wet ballmill and then dried and calcined in air at $950^{\circ} \mathrm{C}$ for $5 \mathrm{~h}$. The calcined powders were pulverized and mixed with the $\mathrm{La}_{2} \mathrm{O}_{3}$ and $\mathrm{Nb}_{2} \mathrm{O}_{5}$ powders to obtain the composition with $\mathrm{Li}_{x} \mathrm{La}_{(1-x) / 3} \mathrm{NbO}_{3}$ (LLNbO100 $x$ for $x=0.10$ and 0.20: LLNbO10 and LLNbO20). The mixed powder was calcined in air at $1200^{\circ} \mathrm{C}$ for $20 \mathrm{~h}$. The calcined powders were charged into platinum or iridium crucibles $(50 \mathrm{~mm}$ in diameter and height). We attempted to grow these single crystals using the conventional RF-heating $\mathrm{Cz}$ method. The seeds were LLNbO10 and LLNbO20 ceramic bars for each growth process. The pulling rate and rotation rate were $1.0-1.5 \mathrm{~mm} / \mathrm{h}$ and $10 \mathrm{rpm}$, respectively. The phases of the as-grown crystals were identified by powder X-ray diffraction (XRD). Based on the results of this experiment and those in recent studies, ${ }^{21), 27)}$ we selected the LLNbO20 composition for further crystal growth.

We determined the optimum composition around LLNbO20 for bulk crystal growth by the $\mathrm{Cz}$ method through the following process. The powders of the composition with $\mathrm{LLNbO} 20+y \mathrm{La}_{2} \mathrm{O}_{3}[y=-0.007,-0.004$, 0 (LLNbO20), 0.004] were prepared, as demonstrated in Fig. 2 and Table 1. The calcined powders were placed in a
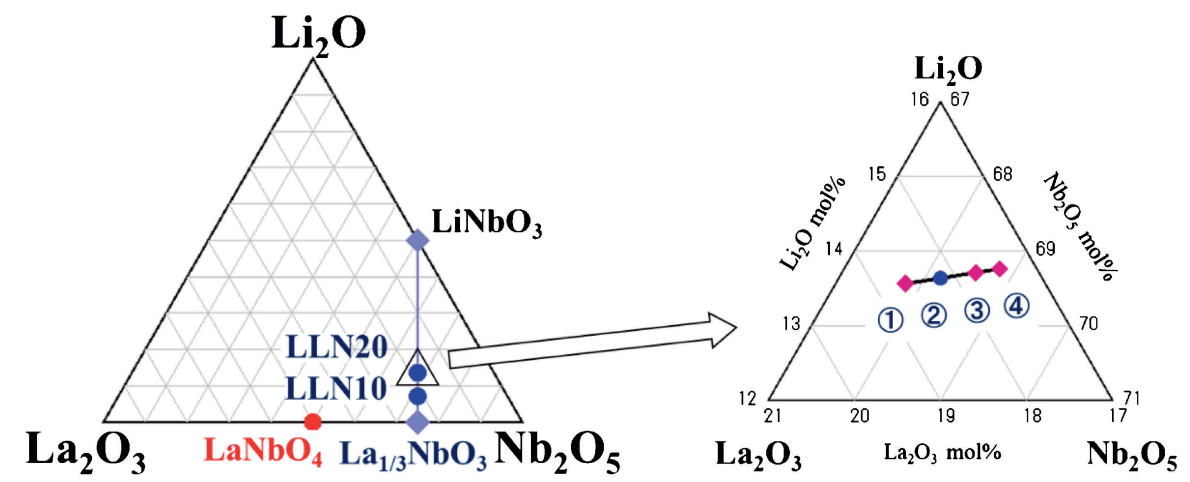

Fig. 2. (a) Ternary plot of the $\mathrm{Li}_{2} \mathrm{O}-\mathrm{La}_{2} \mathrm{O}_{3}-\mathrm{Nb}_{2} \mathrm{O}_{5}$ system and (b) its enlarged figure around LLNbO20. Solid circles with the number indicating compositions where the growth experiment was performed. The detailed compositions are listed in Table 1.

Table 1. Starting melt composition, $\mathrm{La}_{2} \mathrm{O}_{3}$ mole shift from LLNbO20, and melting solidification experiment results

\begin{tabular}{cccccc}
\hline $\begin{array}{c}\text { Composition } \\
\text { no. }\end{array}$ & $\begin{array}{c}\mathrm{Li}_{2} \mathrm{O} \\
(\mathrm{mol} \%)\end{array}$ & $\begin{array}{c}\mathrm{Nb}_{2} \mathrm{O}_{5} \\
(\mathrm{~mol} \%)\end{array}$ & $\begin{array}{c}\mathrm{La}_{2} \mathrm{O}_{3} \\
(\mathrm{~mol} \%)\end{array}$ & LLNbO20 $+y \mathrm{La}_{2} \mathrm{O}_{3}$ & $\begin{array}{l}\text { Secondary phases } \\
\text { in the solidified melts }\end{array}$ \\
\hline 1 & 13.56 & 67.81 & 18.63 & 0.004 & $\mathrm{LaNbO}_{4}, \mathrm{LiNbO}_{3}$ \\
2 & 13.64 & 68.18 & 18.18 & 0 & $\mathrm{LaNbO}_{4}, \mathrm{LiNbO}_{3}$ \\
3 & 13.71 & 68.56 & 17.73 & -0.004 & $\mathrm{LiNbO}_{3}, \mathrm{LiNb}_{3} \mathrm{O}_{8}$ \\
4 & 13.76 & 68.81 & 17.43 & -0.007 & $\mathrm{LiNbO}_{3}, \mathrm{LiNb}_{3} \mathrm{O}_{8}$ \\
\hline
\end{tabular}


platinum crucible and further fired in air at $1300^{\circ} \mathrm{C}$ for $2 \mathrm{~h}$ and cooled in a furnace at a rate of $2^{\circ} \mathrm{C} / \mathrm{min}$. The powders were molten and solidified through this process. In this study, this series of steps is called the melting solidification experiment. The composition of the resulting solidified compounds was analyzed by electron microprobe analysis (EPMA) and the compounds were pulverized. Subsequently, we identified their crystalline phases using powder XRD analysis.

Based on the results of the melting solidification experiment, $\mathrm{LLNbO} 20+y \mathrm{La}_{2} \mathrm{O}_{3}$ with $y=-0.004$ single crystals were grown using the $\mathrm{Cz}$ method. The raw materials, mixing and calcining process, and growth conditions were the same as aforementioned. The growth atmosphere was an air gas flow of $10^{-3} \mathrm{~m}^{3} / \mathrm{min}$. The seed was an LLNbO20 ceramic bar. The phase of the as-grown crystals was identified by powder XRD and their density was measured using the Archimedes method with distilled water at room temperature $(296 \mathrm{~K})$. The crystals grown were cut along [100] and [001] using a backscattering Laue XRD and a wire saw. After polishing and sputtering Au on the crystal surfaces, samples with (100) and (001) planes were fabricated. The lithium-ion conductivity was measured using an ac complex impedance method using an HP4194A impedance/gain phase analyzer over the frequency range of 40-110 MHz. The temperature range was $306-403 \mathrm{~K}$. The measurements were performed in air. We plotted the values of the imaginary part of the impedance against the real part. The data exhibited a straight line at low frequencies and a distorted semicircle at higher frequencies. The resistance was recorded as the value of $Z^{\prime}$ at the intersection between the $Z^{\prime}$ axis and the extrapolation of the semicircle or the linear portion of the plot.

\section{Results and discussion}

The calcined LLNbO10 and LLNbO20 powders before crystal growth were composed solely of perovskite LLNbO phase. After the crystals were grown using the $\mathrm{Cz}$ method with the LLNbO10 and LLNbO20 powders as starting materials, all the boules grown were white and opaque. The powder XRD analysis of the pulverized boules exhibited them to be a mixture of LLNbO and $\mathrm{LaNbO}_{4}$. It has been reported that the melting point of $\mathrm{LaNbO}_{4}\left(1620^{\circ} \mathrm{C}\right)$ is higher than that of LLNbO (1300$\left.1400{ }^{\circ} \mathrm{C}\right) .{ }^{25)}$ Therefore, it was assumed that $\mathrm{LaNbO}_{4}$ precipitated first and then, the LLNbO phase was solidified during the growth process. Furthermore, the powder XRD analysis showed that the amount of $\mathrm{LaNbO}_{4}$ in the boule grown from the LLNbO20 melt was smaller than that from the LLNbO10 melt. It was assumed that the precipitation of $\mathrm{LaNbO}_{4}$ could be prevented by reducing the amount of $\mathrm{La}_{2} \mathrm{O}_{3}$ in the starting material composition. Therefore, for determination of the optimal composition, the melting solidification experiment was conducted using powders with the composition LLNbO20 $+y \mathrm{La}_{2} \mathrm{O}_{3}$.

Then, all solidified compounds with the composition LLNbO20 $+y \mathrm{La}_{2} \mathrm{O}_{3}$ comprised the perovskite LLNbO phase primarily and contained phases of small impurity

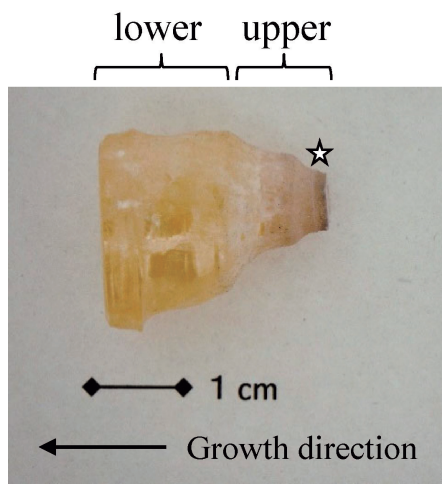

Fig. 3. LLNbO20 crystal boule synthesized using the $\mathrm{Cz}$ method. The starting melt composition was LLNbO20 $+y \mathrm{La}_{2} \mathrm{O}_{3}$ with $y=-0.004$ corresponding to composition no. 3 in Table 1 . The plain star represents the part of the boule used for powder XRD measurement.

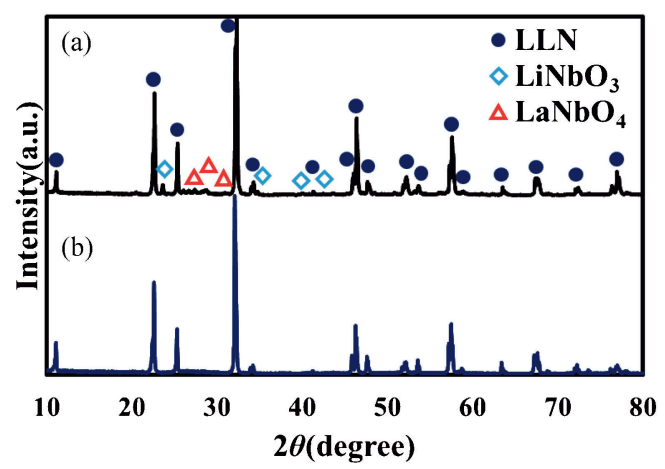

Fig. 4. Powder XRD profiles of pulverized LLNbO20 crystal boule of (a) the rim and (b) center of the part represented by the plain star in Fig. 3.

amounts as shown in Table 1 . The impurity phases were $\mathrm{LaNbO}_{4}$ and $\mathrm{LiNbO}_{3}$ in the $\mathrm{LLNbO} 20+y \mathrm{La}_{2} \mathrm{O}_{3}$ samples with $y=0.004$ and 0 . The LLNbO20 $+y \mathrm{La}_{2} \mathrm{O}_{3}$ samples with $y=-0.004$ and -0.007 contained $\mathrm{LiNbO}_{3}$ and $\mathrm{LiNb}_{3} \mathrm{O}_{8}$. The melting point of $\mathrm{LiNbO}_{3}$ and peritectic point of $\mathrm{LiNb}_{3} \mathrm{O}_{8}$ were less than $1300{ }^{\circ} \mathrm{C}$. It was assumed that these two phases occurred because the cooling rate was higher than that of the $\mathrm{Cz}$ method. Moreover, the powder XRD analysis showed that the LLNbO20 $+y \mathrm{La}_{2} \mathrm{O}_{3}$ sample with $y=-0.004$ had the lowest volume of impurity phases. We attempted to grow perovskite LLNbO20 single crystals using the starting material with the composition $\mathrm{LLNbO} 20+y \mathrm{La}_{2} \mathrm{O}_{3}$ with $y=-0.004$.

Figure 3 shows the as-grown LLNbO20 crystal boule fabricated by the $\mathrm{Cz}$ method; the maximum diameter was $20 \mathrm{~mm}$ and the length was $23 \mathrm{~mm}$. The upper region of the LLNbO20 crystal was opaque while the lower half was transparent and yellow. The upper regions comprised the rim and other parts. The thickness of the rim was less than $300 \mu \mathrm{m}$. Using EPMA and powder XRD analysis, as shown in Fig. 4(a), it was discovered that the rim contained $\mathrm{LaNbO}_{4}$ and $\mathrm{LiNbO}_{3}$ as impurity phases analogous with the melting solidification experiment results. However, the volume of the impurity phases was approximately 


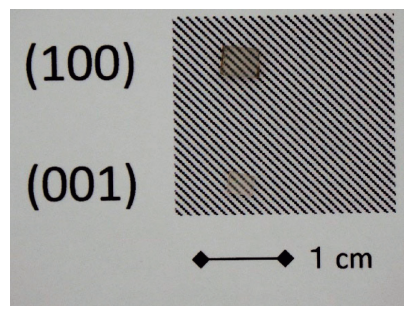

Fig. 5. Crystal substrates with (100) and (001) planes cut from the crystal shown in Fig. 3.

$0.1 \%$ of the starting materials. No inclusion was observed inside the other part of the upper region and the lower region of the LLNbO20 crystal boule, as observed in Fig. 4(b). The lower region of the boule contained four developed flat surfaces, which comprised of planes parallel to the growth direction. Backscattering Laue X-ray analysis demonstrated that the flat surfaces corresponded to the $\{100\}$ plane. Although the seed was the LLNbO20 ceramics bar, the boule grown comprised of single crystals except in the rim. Thus, the LLNbO20 crystal grows preferentially along the $\langle 001\rangle$ direction and a boule composed of single crystals can be obtained easily when the seed is also a single crystal. Large cracks can be observed in Fig. 3. This was owing to the intentional increment in the volume of the crystal. All the peaks in the XRD patterns of the crystal powder corresponded with those of the perovskite LLNbO structure, as shown in Fig. 4(b). Further bulk crystal growth is in progress.

Figure 5 shows crystal substrates with (100) and (001) planes cut from the crystal shown in Fig. 3. Macro-defects were carefully eliminated through appropriate sample fabrication process such as cutting and polishing. The crystal density was $5.042 \mathrm{~g} \mathrm{~cm}^{-3}$. The X-ray structure analysis shows that the lattice parameters were $a=3.909(1)$ and $c=7.891(3) \AA$; the estimated standard deviations are mentioned in parentheses. From the relationship between the $\mathrm{Li}$ concentration and lattice parameters, ${ }^{11)}$ the Li concentration of the LLNbO20 crystal was determined to be $x=$ 0.15 . It has been reported that the melting point of LLNbO decreased as the concentration $x$ of Li increased. ${ }^{27}$ ) The $\mathrm{Li}$ concentration may be shifted from the molten starting material owing to the crystal growth temperature, which indicates that the segregation coefficient $k_{\mathrm{Li}}$ is less than unity in the LLNbO perovskite structure from the melt to the crystal.

Figure 6(a) presents the complex ac impedance plots for the sample along [100] $(/ / a)$ and [001] $(/ / c)$. From these plots, $\sigma$ at $306 \mathrm{~K}$ were determined as $\sigma_{[100]}=2.8 \times$ $10^{-4} \mathrm{~S} \mathrm{~cm}^{-1}$ and $\sigma_{[001]}=9.7 \times 10^{-5} \mathrm{~S} \mathrm{~cm}^{-1}$. The ionic conductivity of the LLNbO single crystals was anisotropic with $\sigma_{[100]} / \sigma_{[001]}=2.9$, which is the intermediate value between the LLNbO single crystals grown using the traveling solvent floating zone $(1.6)^{23)}$ and Bridgman methods (9.4). ${ }^{21)}$ The Arrhenius plots of the ionic conductivities are presented in Fig. 6(b). The ionic conductivity obeys the Arrhenius relation at the measurement temperature range. The $E_{\mathrm{a}}$ values were obtained from a least-squares fit of the
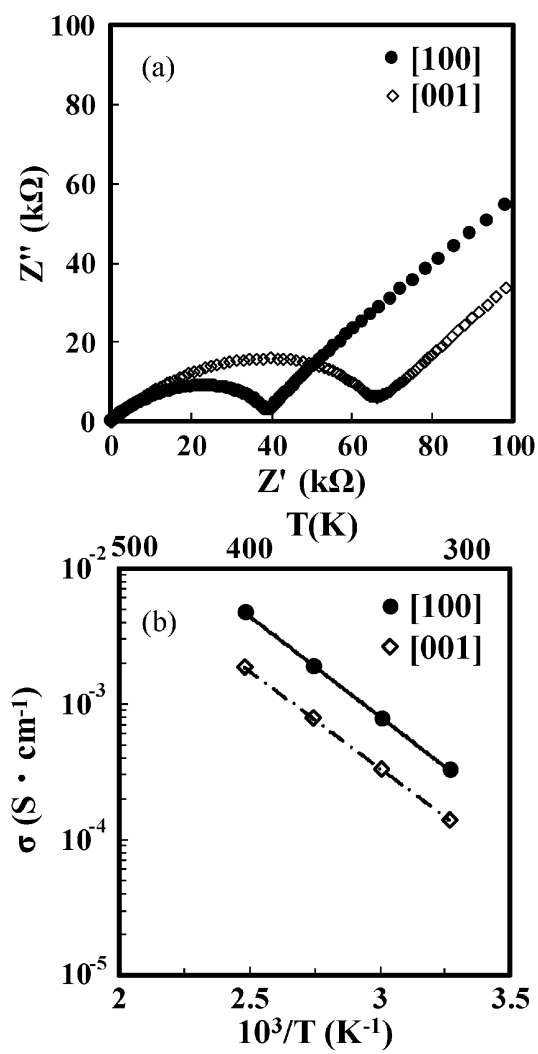

Fig. 6. (a) Impedance plots and (b) Arrhenius plots of lithiumion conductivity for LLNbO20 single crystal at $298 \mathrm{~K}$. Filled circles and plain rhombi represent data along [100] $(/ / a)$ and [001] $(/ / c)$, respectively.

conductivity data using the formula $\sigma=\operatorname{Aexp}\left(-E_{\mathrm{a}} / k_{\mathrm{B}} T\right)$. The activation energies $E_{\mathrm{a}[100]}$ and $E_{\mathrm{a}[001]}$ for the LLNbO20 single crystal were 0.29 and $0.28 \mathrm{eV}$, respectively. These values are lower than those of the LLNbO single crystal $\left(0.34 \mathrm{eV}^{20), 23)}\right)$ and polycrystalline materials $\left(0.36 \mathrm{eV}^{11)}\right)$. The activation energy of lithium-ion conductivity of LLNbO single crystals is isotropic, with $E_{\mathrm{a}[100]} / E_{\mathrm{a}[100]}=$ 1.03, and it is similar to that of (1.06) in the LLTO single crystal. ${ }^{19)}$ In the LLTO-based oxides, Inaguma et al. ${ }^{28)}$ reported that the ratios of lithium to vacancy concentration and site percolation are predominant factors in lithiumion conductivity. In terms of site percolation, $\sigma$ obeys the following relation: ${ }^{29)}$

$$
\sigma \propto\left(n-n_{\mathrm{c}}\right)^{\mu}
$$

where $n$ is the sum of lithium and vacancy concentrations and $n_{\mathrm{c}}$ is the threshold. When $n_{\mathrm{c}}=0.3$ and $\mu=2$, the variety of lithium-ion conductivities in the LLTO-based oxide are detailed in. ${ }^{28)} n_{\mathrm{c}}=0.3$ was applied for a simple cubic lattice and the exponent $\mu=2$ implied threedimensional conduction. If the conduction occurred twodimensionally, then $\mu$ must be $4 / 3$. In terms of site percolation, the deference of $\mu$ could produce an anisotropic lithium-ion conductivity because the activation energy of the lithium-ion conductivity was isotropic. It was assumed that the longitudinal and lateral migrations of the lithium ion were three and two-dimensional, respectively. 


\section{Conclusion}

In this study, we synthesized an LLNbO single crystal in air using the $\mathrm{Cz}$ method. The starting material was a Lapoor composition. The crystals grown were inclusion-free and yellow. The Li concentration $(x=0.15)$ in the crystals was lower than that in the starting materials $(x=0.20)$ because the segregation coefficient $k_{\mathrm{Li}}$ was less than 1 in the LLNbO perovskite structure from the molten to the crystal phase. The ionic conductivity of the LLNbO single crystals was anisotropic with $\sigma_{[100]} / \sigma_{[001]}=2.9$ for $x=$ 0.15 . The anisotropic conductivity was explained using percolation theory. Because $\sigma_{[100]}=2.8 \times 10^{-4} \mathrm{~S} \mathrm{~cm}^{-1}$, and the crystal was easily grown using the $\mathrm{Cz}$ method, the LLNbO crystal can be used as a substrate for the solid electrolyte of LIBs.

Acknowledgment This work was supported by JSPS KAKENHI-Grant Numbers 16H02394 and 19H05515.

\section{References}

1) P. Knauth, Solid State Ionics, 180, 911-916 (2009).

2) J. G. Kim, B. Son, S. Mukherjee, N. Schuppert, A. Bates, O. Kwon, M. Jong Choi, H. Y. Chung and S. Park, J. Power Sources, 282, 299-322 (2015).

3) K. Kataoka, H. Nagata and J. Akimoto, Sci. Rep., 8, 9965 (2018).

4) Y. Kato, S. Hori, T. Saito, K. Suzuki, M. Hirayama, A. Mitsui, M. Yonemura, H. Iba and R. Kanno, Nat. Energy, 1, 16030 (2016).

5) L. Latie, G. Villeneuve, D. Conte and G. Le Flem, J. Solid State Chem., 51, 293-299 (1984).

6) S. Stramare, V. Thangadurai and W. Weppner, Chem. Mater., 15, 3974-3990 (2003).

7) M. Itoh, Y. Inaguma, W. Jung, L. Che and T. Nakamura, Solid State Ionics, 70, 203-207 (1994).

8) Y. Inaguma, Y. Matsui, Y. Shan, M. Itoh and T. Nakamura, Solid State Commun., 86, 689-693 (1993).

9) Y. Inaguma, Y. Matsui, Y.-J. Shan, M. Itoh and T. Nakamura, Solid State Ionics, 79, 91-97 (1995).

10) Y. Inaguma, J. Yu, Y. Shan, M. Itoh and T. Nakamura, J. Electrochem. Soc., 142, L8-L11 (1995).
11) Y. Kawakami, H. Ikuta and M. Wakihara, J. Solid State Electr., 2, 206-210 (1998).

12) A. Belous, E. Pashkova, O. Gavrilenko, O. V'yunov and L. Kovalenko, Ionics, 9, 21-27 (2003).

13) S. Garcı-Martın, J. M. Rojo, H. Tsukamoto, E. Morán and M. A. Alario-Franco, Solid State Ionics, 116, 11-18 (1999).

14) M. Nakayama, K. Imaki, H. Ikuta, Y. Uchimoto and M. Wakihara, J. Phys. Chem. B, 106, 6437-6441 (2002).

15) M. Nakayama, H. Ikuta, Y. Uchimoto and M. Wakihara, Appl. Phys. Lett., 84, 4227-4229 (2004).

16) M. Nakayama, M. Wakihara, Y. Kobayashi and $H$. Miyashiro, J. Phys. Chem. B, 109, 14648-14653 (2005).

17) R. Murugan, V. Thangadurai and W. Weppner, Angew. Chem. Int. Edit., 46, 7778-7781 (2007).

18) J. Awaka, N. Kijima, H. Hayakawa and J. Akimoto, J. Solid State Chem., 182, 2046-2052 (2009).

19) Y. Inaguma, J. Yu, T. Katsumata and M. Itoh, J. Ceram. Soc. Jpn., 105, 548-550 (1997).

20) Y. Fujiwara, K. Hoshikawa and K. Kohama, J. Cryst. Growth, 433, 48-53 (2016).

21) Y. Fujiwara, T. Taishi, K. Hoshikawa, K. Kohama and H. Iba, Jpn. J. Appl. Phys., 55, 090306 (2016).

22) Y. Maruyama, S. Minamimure, C. Kobayashi, M. Nagao, S. Watauchi and I. Tanaka, R. Soc. Open Sci., 5, 181445 (2018).

23) M. S. Ali, N. Sato, I. Fukasawa, Y. Maruyama, M. Nagao, S. Watauchi and I. Tanaka, Cryst. Growth Des., 19, 6291-6295 (2019).

24) K. Kataoka and J. Akimoto, J. Ceram. Soc. Jpn., 127, 521-526 (2019).

25) E. P. Savchenko, N. A. Dodina and E. K. Keler, in "Chemistry of high temperature materials", Ed. by N. A. Topo rov, Consultants Bureau, New York (1969) pp. 108-113.

26) P. N. Iyer and A. J. Smith, Acta Crystallogr., 23, 740746 (1967).

27) I. Tanaka, R. Yoshihara, C. Nakazawa, M. Nagao and S. Watauchi, J. Cryst. Growth, 507, 251-254 (2019).

28) Y. Inaguma and M. Itoh, Solid State Ionics, 86-88, 257260 (1996).

29) D. Stauffer, A. Aharony, "Introduction to PERCOLATION THEORY" (1994). 